\title{
Zinc and Lifestyle - Related Disease - with Focus on Diabetes Mellitus and Osteoporosis
}

\author{
Yutaka Yoshikawa*, Hiroki Murakami, Shigeyuki Fujimoto, Kanako Michigami, and Hiroyuki Yasui \\ Department of Analytical and Bioinorganic Chemistry, Division of Analytical and Physical Chemistry, Kyoto Pharmaceutical University, Japan
}

\begin{abstract}
In recent years, more people worldwide have suffered from diseases such as cancer, myocardial infarction, hypertension, osteoporosis, and diabetes mellitus. Diabetes mellitus and osteoporosis, well known as lifestyle-related diseases, have been considered serious problems in particular because full recovery is difficult. In 2007, the number of diabetes mellitus patients worldwide was reported to be approximately 200 million. Osteoporosis patients also amounted to approximately 200 million people worldwide. Against this background, many kinds of minerals have been used in the treatment and/or prevention of these lifestyle-related diseases. In particular, though the abundance of zinc in the body is very large, thus it is presumed to have a wide safety margin. Known as the second messenger, zinc has a wide variety of physiological functions, and attracts attention as an alternative to drug biological components. In this review, we outline the effect of zinc on the lifestyle-related diseases diabetes and osteoporosis.
\end{abstract}

Keywords: Osteoporosis; Diabetes; Biomolecules; Autoimmune disease

\section{Introduction}

The number of lifestyle-related diseases has been increasing globally as a result of recent drastic changes in lifestyle, diet, and increased possession of driver's licenses. In particular, it is an important problem that the lives of diabetes mellitus (DM) patients may be shortened when such patients are associated with other diseases (hypertension or hyperlipidemia) [1]. DM is a disease associated with absolute or relative insulin deficiency, and various types of medicines to treat DM have been developed worldwide. The World Health Organization (WHO) has classified DM into 2 types, namely, type 1 and type $2 \mathrm{DM}$. Type $1 \mathrm{DM}$ is an autoimmune disease characterized by $\beta$-cell destruction, and insulin injections are administered for its management, whereas type $2 \mathrm{DM}$ refers to adult-onset DM caused by defective insulin sensitivity, which is managed by the administration of several types of organic medicines [2-5]. A very important aspect of $\mathrm{DM}$ is that it leads to serious life-threatening complications, causing severe damage to the heart, eyes, kidneys, blood vessels, nerves, gums, teeth, feet, and legs [6,7]. There is also the fear of an increase in the incidence of osteoporosis as the population ages [8]. The WHO defines osteoporosis as a systemic degeneration of the skeleton, characterized by the loss of bone mass (in both organic and mineral bone components) and the structural degeneration of bone tissue that leads to an increase in bone fractures [9]. The risk of fracture is also increased by factors such as lifestyle, drug treatments, family history, and other conditions that cause secondary osteoporosis. About $40 \%$ of women in developed countries will experience an osteoporosis-related fracture in the course of their lifetime, with men facing approximately one-third to one-half the risk of women [10]. In recent years, it has been reported that adequate calcium and vitamin $\mathrm{D}$ intake are essential if a specific treatment is established. Insufficient calcium intake and/ or poor vitamin $\mathrm{D}$ status represent the most common condition of non-responders to conventional anti-osteoporotic therapies [11]. Recently, medicines containing metals, such as cisplatin with platinum, auranofin with aurum, and promac with zinc, have been developed and used clinically [12-14]. Among them, zinc is known as one of the most important essential trace elements of all biological systems, and is less toxic than the other trace elements [15]. Among the many physiological and nutritional roles of zinc, zinc ions have been found to stimulate lipogenesis in rat adipocytes in a manner similar to the action of insulin. Zinc also plays an important role in infant development.
Furthermore, it has been demonstrated that zinc plays an important role in bone metabolism-regulating factors [16].

\section{Anti Diabetic Activity of Zinc and its Complexes}

At present, therapy for type $2 \mathrm{DM}$ relies mainly on several medicines intended to reduce high blood glucose in addition to diet and exercise. For instance, the therapy may include medicines such as dipeptidyl peptidase IV inhibitors, which enhance insulin secretion; sulphonylureas, which increase insulin release from the pancreatic islets; thiazolidinediones, which enhance insulin action; and a-glucosidase inhibitors, which interfere with glucose absorption in the small intestine [17-20]. These medicines have limited efficacy and significant mechanism-based side effects such as hypoglycemia and hepatopathy. In the course of the search for new pharmaceuticals, several metal ions and their complexes have been found to exhibit an antidiabetic effect in in vitro and in vivo systems. Currently, the most consistent finding, which has been observed in diabetic animal models such as rats and mice as well as in human diabetic patients, is the increased urinary excretion of zinc in diabetic subjects compared to controls. In DM studies, many researchers have thus recognized very clearly that zinc is an essentially important factor. In 1980, zinc was found to stimulate rat adipocyte lipogenesis similar to the action of insulin [21], which was followed by observations on the in vivo antidiabetic effects of oral zinc chloride $\left(\mathrm{ZnCl}_{2}\right)$ in streptozotocin (STZ) rats and ob/ob mice in 1992 and 1998, respectively [22,23]. Simon and Taylor [24] reported that dietary zinc supplementation decreased high blood glucose in $\mathrm{db} / \mathrm{db}$ mice, but that these administration doses were very high doses that exceeded the median lethal dose. As the bioavailability of $\mathrm{ZnCl}_{2}$ is relatively low, the complexation of zinc has been attempted. Metal complexes as metallo drugs are required to possess high bioavailability, to which there are

*Corresponding author: Yutaka Yoshikawa, Department of Analytical and Bioinorganic Chemistry, Division of Analytical and Physical Chemistry, Kyoto Pharmaceutical University, Japan, E-mail: yutaka@mb.kyoto-phu.ac.jp

Received March 01, 2013; Accepted March 03, 2013; Published March 18, 2013

Citation: Yoshikawa Y, Murakami H, Fujimoto S, Michigami K, Yasui H (2013) Zinc and Lifestyle - Related Disease - with Focus on Diabetes Mellitus and Osteoporosis. Vitam Miner S6: 002. doi:10.4172/2376-1318.S6-002

Copyright: (c) 2013 Yoshikawa Y, et al. This is an open-access article distributed under the terms of the Creative Commons Attribution License, which permits unrestricted use, distribution, and reproduction in any medium, provided the original author and source are credited. 
many important contributing factors involving low molecular weight, neutral charge, coordination mode around the metal center, moderate stability constant, and moderate partition coefficient, high stability in the presence of many proteins and other biomolecules, and nontoxicity. Since then, we have proposed a wide variety of zinc complexes with different coordination modes. Zinc complexes with $\mathrm{Zn}\left(\mathrm{N}_{2} \mathrm{O}_{2}\right)$, $\mathrm{Zn}\left(\mathrm{O}_{4}\right), \mathrm{Zn}\left(\mathrm{S}_{2} \mathrm{O}_{2}\right), \mathrm{Zn}\left(\mathrm{N}_{4}\right)$, and $\mathrm{Zn}\left(\mathrm{S}_{4}\right)$ coordination modes have been prepared $[25,26]$ For example, we have synthesized zinc complexes with the $\mathrm{Zn}\left(\mathrm{N}_{4}\right)$ coordination mode. Bis (2-aminomethylpyridinato) $\mathrm{Zn}\left(\left[\mathrm{Zn}(2 \text {-ampy })_{2}\right]\right)$, bis(2-aminoethylpyridinato $) \mathrm{Zn}\left(\left[\mathrm{Zn}(2 \text {-aepy })_{2}\right]\right)$, and (1,5,8,12-tetraazadodecanato) $\mathrm{Zn}$ ([Zn(1,5,8,12-td)]) complexes have been proposed [27]. Saha et al. [28] found that water-soluble (meso-tetrakis[4-sulfonatophenyl]porphyrinato)Zn ([Zn(tpps)]), in which the zinc coordination sphere is $\mathrm{Zn}\left(\mathrm{N}_{4}\right)$, was a potential insulin-mimetic $\mathrm{Zn}$-porphyrin complex to treat $\mathrm{KKA}^{\mathrm{y}}$ mice when introduced by oral gavage. Bis(pyrrolidine dithiocarbamato) $\mathrm{Zn}$ $\left(\left[\mathrm{Zn}(\mathrm{pdc})_{2}\right]\right)$ complex with the $\mathrm{Zn}\left(\mathrm{S}_{4}\right)$ coordination mode exhibited high hypoglycemic activities when orally administered to $\mathrm{KKA}^{y}$ mice [29]. On the other hand, we have focused on bis(hinokitiolato) zinc $\left(\left[\mathrm{Zn}(\mathrm{hkt})_{2}\right]\right)$, a complex with a $\mathrm{Zn}\left(\mathrm{O}_{4}\right)$ coordination mode that has been reported to have higher insulin-mimetic activity relative to zinc complexes with the $\mathrm{Zn}\left(\mathrm{O}_{4}\right)$ coordination mode [30]. Hinokitiol is a ligand of $\left[\mathrm{Zn}(\mathrm{hkt})_{2}\right]$, and is known to be a tropolone-related compound with an aromatic 7 -member ring. It was reported that the hinokitiol and tropolone obtained from Aomori cypress tar acids have antibacterial and antioxidant activities $[31,32]$. In our study, tropolone-related zinc complexes with the $\mathrm{Zn}\left(\mathrm{O}_{4}\right)$ coordination mode, including hinokitiol or tropolone, were converted into complexes with the $\mathrm{Zn}\left(\mathrm{S}_{2} \mathrm{O}_{2}\right)$ coordination mode, and their insulin-mimetic activity $\left(\mathrm{IC}_{50}\right.$ value) was evaluated by measuring the inhibition of free fatty acid (FFA) release and enhancement of glucose uptake in isolated rat adipocytes $\left(\mathrm{EC}_{50}\right.$ value), and their antidiabetic effect in vivo. Among the complexes, the bis(thiotoropolonato) $\mathrm{Zn}\left(\left[\mathrm{Zn}(\operatorname{ttrp})_{2}\right]\right)$ complex with the $\mathrm{Zn}\left(\mathrm{S}_{2} \mathrm{O}_{2}\right)$ coordination mode was identified from among several prepared complexes by in vitro evaluations, in which the $\left[\mathrm{Zn}(\mathrm{ttrp})_{2}\right]$ complex exhibited 10-fold higher activity than that of the $\left[\mathrm{Zn}(\operatorname{trp})_{2}\right]$ complex in regard to the suppression of FFA release in the adipocytes (Figure 1) [33]. In addition, blood glucose levels were improved, and hemoglobin Alc (HbAlc), which is indicative of average blood glucose levels, was also improved when $\left[\mathrm{Zn}(\operatorname{ttrp})_{2}\right]$ was administered to type 2 diabetic $\mathrm{KKA}^{\mathrm{y}}$ mice for 25 days [33]. Other interesting anti diabetic zinc complexes have recently been proposed (Figure 2). For example, zinc as a component of prostate extract enhanced glucose utilization in STZ-diabetic rats and improved their diabetic condition, which indicates that other substances present in the prostate extract, such as $[\mathrm{Zn} / \mathrm{cyclo}$ (His-Pro)], might also contribute to the positive effects on the diabetic state [34]. Moreover, it has been reported that bis(N-hydroxy-4-[(trifluoromethylsulfonamido)methyl]benzamidato) $\mathrm{Zn}\left(\left[\mathrm{Zn}(\mathrm{h}-4-\mathrm{tmn}-\mathrm{b})_{2}\right]\right)$ complex activates Akt phosphorylation and exhibits insulin-like activity [35]. An especially interesting finding regarding the antidiabetic effect of zinc complexes was obtained in 2013 by us. Based on past studies, we synthesized a new zinc complex based on lipophilicity, stability, and the hard and soft acids and bases rule. The complex was a bis(2-selenopyridine- $N$-oxidato) $\mathrm{Zn}$ $\left(\left[\mathrm{Zn}(\mathrm{spno})_{2}\right]\right)$ complex, which is an analog of bis(2-hydroxypyridineN-oxidato $) \mathrm{Zn}\left(\left[\mathrm{Zn}(\mathrm{hpno})_{2}\right]\right)$ with a $\mathrm{Zn}\left(\mathrm{O}_{4}\right)$ coordination mode or bis(2-mercaptopyridine-N-oxidato) $\mathrm{Zn}\left(\left[\mathrm{Zn}(\mathrm{mpno})_{2}\right]\right)$ with a $\mathrm{Zn}\left(\mathrm{S}_{2} \mathrm{O}_{2}\right)$ coordination mode, and has a $\mathrm{Zn}\left(\mathrm{Se}_{2} \mathrm{O}_{2}\right)$ coordination mode. Analyses of the structure-activity relationships between their insulin-mimetic activity and the coordination modes of their related complexes showed that $\left[\mathrm{Zn}(\text { spno })_{2}\right]$ had highest insulin-mimetic activity (Figure 3) [36].

\begin{tabular}{|c|c|c|}
\hline name & [Zn(trp)2] & [Zn(ttrp)2] \\
\hline $\mathrm{IC}_{50}(\mu \mathrm{M})$ & $113 \pm 4$ & $12 \pm 1$ * \\
\hline $\mathrm{EC}_{50}(\mu \mathrm{M})$ & $72 \pm 9$ & $0.7 \pm 0.1^{*}$ \\
\hline
\end{tabular}

Figure 1: Estimated $\mathrm{IC}_{50}$ and $\mathrm{EC}_{50}$ values of tropolone related zinc complexes for inhibition of free fatty acids release and enhancement of glucose uptake, respectively in isolated rat adipocytes. Significance at ${ }^{*} p<0.01$, vs $\operatorname{Zn}\left[(\operatorname{trp})_{2}\right]$ Data are expressed as mean \pm SDs for three runs.

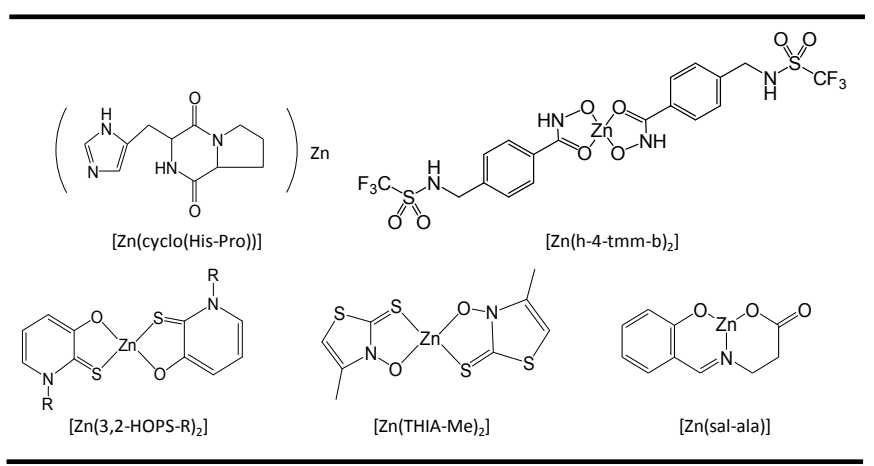

Figure 2: Anti-diabetic new zinc complexes with different coordination modes.



Figure 3: Estimated $\mathrm{IC}_{50}$ values of pyridine $\mathrm{N}$-oxide related zinc complexes for inhibition of free fatty acids release in isolated rat adipocytes. Significance at ${ }^{\#} \mathrm{p}<0.001$, vs $\left[\mathrm{Zn}(\mathrm{hpno})_{2}\right]$. Data are expressed as mean $\pm \mathrm{SDs}$ for three runs.

We evaluated the antidiabetic effects of $\left[\mathrm{Zn}(\mathrm{spno})_{2}\right]$ using a lower oral dose (1.25-2.5 mg Zn/kg body weight), unlike previous studies on KKAy mice [36]. The HbA1c levels in the treatment group decreased considerably compared to those in the control group (Figure 4). These results indicate that $\left[\mathrm{Zn}(\mathrm{spno})_{2}\right]$ has the most effective hypoglycemic effects among the known zinc complexes. Conducting a human study involving the use of zinc complexes by diabetic patients would be a future research aim.

\section{Implication of Zinc and Bone Metabolism in Osteoporosis}

Osteoporosis is a disease involving genetics, endocrine function, exercise, and nutritional considerations. In this disease, the bones become porous, brittle, and susceptible to breaking. Osteoporosis itself is not a disease that threatens a person's life as cancer, stroke, and myocardial infarction, but many people require nursing care due to osteoporosis-related bone fractures. The quality of life of such individuals decreases remarkably. Thus, many approaches are being employed to reduce bone fracture risks in patients with osteoporosis $[37,38]$. An example of drug therapies is as follows. Bisphosphonates are potent inhibitors of bone resorption used mainly in the treatment of osteoporosis [39]. Other treatments such as teriparatide, raloxifene, 

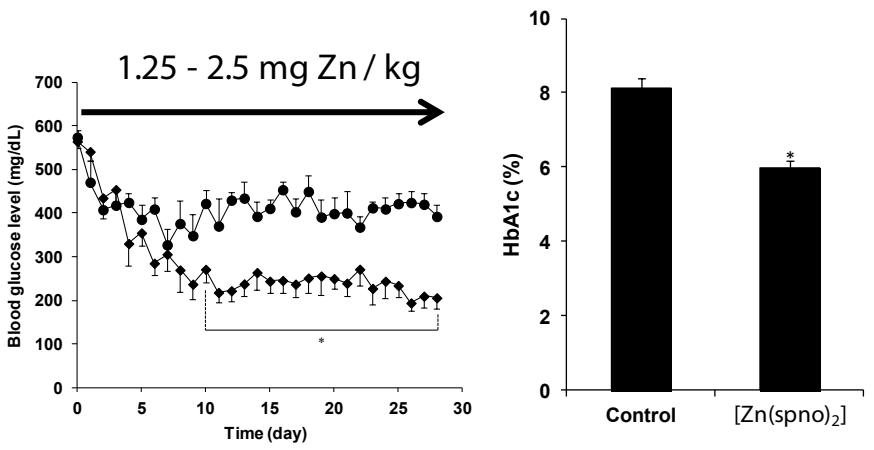

Figure 4: Changes in blood glucose levels (left) and $\mathrm{HbA1c}$ (right) levels in type 2 diabetes KKAy mice treated with PEG400 (control; $\bullet$ ) or [Zn(spno) $\left.)_{2}\right]$ $(\triangleleft)$. Data are expressed as mean \pm SEs for 5-7 mice. Significance at ${ }^{*} p<0.05$ vs control.

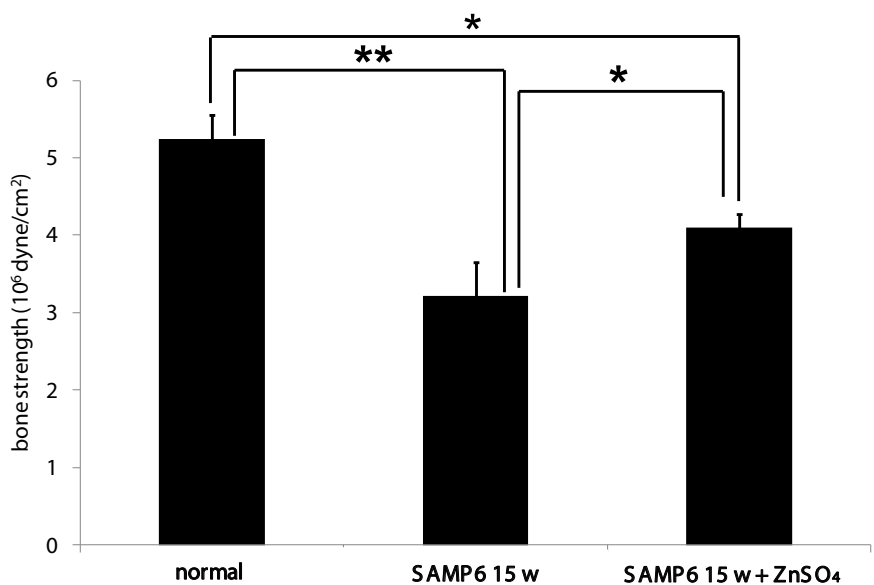

Figure 5: Changes of bone strength in SAMP6 mice treated with $\mathrm{ZnSO}_{4}$ for 8 weeks. Significance at ${ }^{* *} p<0.01,{ }^{*} p<0.05$ vs normal or SAMP6 $15 \mathrm{w}$. Data are expressed as mean \pm SDs for 5-7 mice.

or strontium ranelate are now also available, and new medicines are currently being developed for osteoporosis patients [40]. However, these medicines have severe side effects. Thus, the development of drugs with fewer side effects and accessible supplements is expected. In recent years, it has been reported that various metal ions take an interest in bone metabolism. Tucker et al. [41] reported that magnesium intakes were significantly associated with bone mineral density in 2001 and Zhu et al. [42] also reported that potassium intake shows positive association with bone mineral density in 2009. In addition, many researchers have investigated the influence of zinc on bone metabolism [43-46]. For example, the bone mineral content of the jawbone and bone mechanical strength of the femur in zinc-deficient osteoporosis Sprague Dawley rats were reportedly restored by 12 -week administration of zinc [47]. Yamaguchi and other investigators have reported that the amounts of DNA, an indicator of bone growth, and alkaline phosphatase (ALP) increase after zinc administration, and have proven that zinc effectively treats diabetic abnormal bone metabolism $[48,49]$. In contrast, the influence of other metals (chromium, cobalt, copper, and manganese) on bone metabolism has been noted, but high doses were required to demonstrate the effect of these metals. Thus, the high toxicity of metal ions was apprehended. Zinc was the metal that exerted the best effects on bone metabolism in these reports [50]. In a recent study, when we bred SAMP6 mice (a senescence-accelerated model mouse) treated with $\mathrm{ZnSO}_{4}(25 \mathrm{mg} \mathrm{Zn} / \mathrm{kg}$ body weight) from 7 weeks to 15 weeks of age, the $\mathrm{ZnSO}_{4}$-treated group exhibited improved bone strength, increased ALP activity, and increased bone zinc density compared with the non-treated group (Figure 5) [51]. This result is considered to be related to the osteoplasty promotion effect of zinc and the reinforcement of material strength of the osseous tissue by zinc incorporation into the bone. It was reported that the stability of the collagenous triple helix is increased by metals in artificial collagen model peptides [52]. Thus, enhancement of zinc uptake to the bone stabilizes the collagen, and zinc may strengthen bone that has thinned due to osteoporosis. The world awaits the development of zinc compounds with an anti-osteoporosis effect.

\section{Conclusion}

Zinc is an essential element in the body and is present in amounts of approximately $2 \mathrm{~g}$. Thus, its toxicity is very low and it is easy to use. It has a number of physiological effects and closely relates with human health, as discussed previously. In particular, zinc is closely related to the lifestyle-related diseases diabetes or osteoporosis, and a number of other researchers and we have focused on its effects on these conditions. The zinc complexes we have plans to synthesize will have high bioavailability, and we expect them to have a major effect on these lifestyle-related diseases. Zinc will play an important role in maintaining the health of the body.

\section{Acknowledgement}

The authors are grateful to the members of the Department of Analytical and Bioinorganic Chemistry, Division of Analytical and Physical Chemistry, Kyoto Pharmaceutical University and Department of Sports, Health and Nutrition, Faculty of Health and Welfare, Kobe Women's University.

\section{References}

1. Almgren $T$, Wilhelmsen $L$, Samuelsson $O$, Himmelmann $A$, Rosengren $A$ et al. (2007) Diabetes in treated hypertension is common and carries a high cardiovascular risk: results from a 28-year follow-up. J Hypertens 25: 13111317.

2. Chapman TM, Noble S, Goa KL (2003) Spotlight on insulin aspart in type 1 and 2 diabetes mellitus. Treat Endocrinol 2: 71-76.

3. Alexandraki K, Piperi C, Kalofoutis C, Singh J, Alaveras A, et al. (2006) Inflammatory process in type 2 diabetes: The role of cytokines. Ann N Y Acad Sci 1084: 89-117.

4. Muoio DM, Newgard CB (2006) Obesity-related derangements in metabolic regulation. Annu Rev Biochem 75: 367-401.

5. Kuzuya T, Nakagawa S, Satoh J, Kanazawa Y, Iwamoto Y, et al. (2002) Report of the Committee on the classification and diagnostic criteria of diabetes mellitus. Diabetes Res Clin Pract 55: 65-85.

6. Crosby-Nwaobi R, Sivaprasad S, Forbes A (2012) A systematic review of the association of diabetic retinopathy and cognitive impairment in people with Type 2 diabetes. Diabetes Res Clin Pract 96: 101-110.

7. Nichols GA, Vupputuri S, Lau H (2011) Medical care costs associated with progression of diabetic nephropathy. Diabetes Care 34: 2374-2378.

8. Atik OS, Uslu MM, Eksioglu F, Satana T (2006) Etiology of senile osteoporosis: a hypothesis. Clin Orthop Relat Res 443: 25-27.

9. (1994) Assessment of fracture risk and its application to screening for postmenopausal osteoporosis. Report of a WHO Study Group. World Health Organ Tech Rep Ser 843: 1-129.

10. Kanis JA, Johnell O, Oden A, Sembo I, Redlund-Johnell I, et al. (2000) Longterm risk of osteoporotic fracture in Malmö. Osteoporos Int 11: 669-674.

11. Body JJ, Bergmann P, Boonen S, Devogelaer JP, Gielen E, et al. (2012) Extraskeletal benefits and risks of calcium, vitamin D and anti-osteoporosis medications. Osteoporos Int 23: S1-S23.

12. Frezza M, Hindo S, Chen D, Davenport A, Schmitt S, et al. (2010) Novel metals and metal complexes as platforms for cancer therapy. Curr Pharm Des 16 : 1813-1825. 
Citation: Yoshikawa Y, Murakami H, Fujimoto S, Michigami K, Yasui H (2013) Zinc and Lifestyle - Related Disease - with Focus on Diabetes Mellitus and Osteoporosis. Vitam Miner S6: 002. doi:10.4172/2376-1318.S6-002

13. Furuta S, Toyama S, Miwa M, Sano H (1995) Disposition of polaprezinc (zinc L-carnosine complex) in rat gastrointestinal tract and effect of cimetidine on its adhesion to gastric tissues. J Pharm Pharmacol 47: 632-636.

14. Walz DT, Griswold DE, DiMartino MJ, Bumbier EE (1983) Distribution of gold in rat blood after intravenous administration of auranofin, gold sodium thiomalate and aurothioglucose to rats. J Rheumatol 10: 117-120.

15. McClain C, Morris P, Hennig B (1995) Zinc and endothelial function. Nutrition 11: $117-120$

16. Yamaguchi M (2012) Nutritional factors and bone homeostasis: synergistic effect with zinc and genistein in osteogenesis. Mol Cell Biochem 366: 201-221.

17. Moller DE (2001) New drug targets for type 2 diabetes and the metabolic syndrome. Nature 414: 821-827.

18. Gallwitz B (2006) Therapies for the treatment of type 2 diabetes mellitus based on incretin action. Minerva Endocrinol 31: 133-147.

19. Chen X, Zheng Y, Shen $Y$ (2006) Voglibose (Basen, AO-128), one of the most important alpha-glucosidase inhibitors. Curr Med Chem 13: 109-116.

20. McCall AL (2001) Clinical review of glimepiride. Expert Opin Pharmacother 2: 699-713.

21. Coulson L, Dandona P (1980) Insulin-like effect of zinc on adipocytes. Diabetes 29: 665-667.

22. Shisheva A, Gefel D, Shechter $Y$ (1992) Insulinlike effects of zinc ion in vitro and in vivo. Preferential effects on desensitized adipocytes and induction of normoglycemia in streptozocin-induced rats. Diabetes 41: 982-988.

23. Chen MD, Liou SJ, Lin PY, Yang VC, Alexander PS, et al. (1998) Effects of zinc supplementation on the plasma glucose level and insulin activity in genetically obese (ob/ob) mice. Biol Trace Elem Res 61: 303-311.

24. Simon SF, Taylor CG (2001) Dietary zinc supplementation attenuates hyperglycemia in db/db mice. Exp Biol Med 226: 43-51.

25. Yoshikawa Y, Yasui H (2012) Zinc complexes developed as metallopharmaceutics for treating diabetes mellitus based on the bio-medicinal inorganic chemistry. Curr Top Med Chem 12: 210-218.

26. Sakurai H, Yoshikawa Y, Yasui H (2008) Current state for the development of metallopharmaceutics and anti-diabetic metal complexes. Chem Soc Rev 37: 2383-2392.

27. Yoshikawa $Y$, Kondo M, Sakurai H, Kojima $Y$ (2005) A family of insulinomimetic zinc(II) complexes of amino ligands with $\mathrm{Zn}\left(\mathrm{N}_{\mathrm{n}}\right)(\mathrm{n}=3$ and 4$)$ coordination modes. J Inorg Biochem 99: 1497-1503.

28. Saha TK, Yoshikawa Y, Sakurai H (2007) A [meso-tetrakis(4-sulfonatophenyl) porphyrinato]zinc(ii) complex as an oral therapeutic for the treatment of type 2 diabetic KKA(y) mice. ChemMedChem 2: 218-225.

29. Yoshikawa Y, Adachi Y, Sakurai H (2007) A new type of orally active antidiabetic Zn(II)-dithiocarbamate complex. Life Sci 80: 759-766.

30. Yamane M, Adachi Y, Yoshikawa Y, Sakurai H (2005) A New Anti-diabetic $\mathrm{Zn}(\mathrm{II})$-Hinokitiol ( $\beta$-Thujaplicin) Complex with $\mathrm{Zn}\left(\mathrm{O}_{4}\right)$ Coordination Mode. Chem Lett 34: 1694-1695.

31. Arima Y, Hatanaka A, Tsukihara S, Fujimoto K, Fukuda K, et al. (1997) Scavenging activities of a-, $ß$ - and.-thujaplicins against active oxygen species. Chem Pharm Bull 45: 1881-1886.

32. Osawa K, Matsumoto T, Maruyama T, Takiguchi T, Okuda K, et al. (1990) Studies of the antibacterial activity of plant extracts and their constituents against periodontopathic bacteria. Bull Tokyo Dent Coll 31: 17-21.

33. Murakami H, Yasui H, Yoshikawa Y (2012) Pharmacological and pharmacokinetic studies of anti-diabetic tropolonato- $\mathrm{Zn}(\mathrm{II})$ complexes with $\mathrm{Zn}(\mathrm{S}(2) \mathrm{O}(2))$ coordination mode. Chem Pharm Bull (Tokyo) 60: 1096-1104.
34. Song MK, Rosenthal MJ, Hong S, Harris DM, Hwang I, et al. (2001) Synergistic antidiabetic activities of zinc, cyclo (his-pro), and arachidonic acid. Metabolism 50: 53-59.

35. Georgiades SN, Mak LH, Angurell I, Rosivatz E, Firouz Mohd Mustapa M, et al (2011) Identification of a potent activator of Akt phosphorylation from a nove series of phenolic, picolinic, pyridino, and hydroxamic zinc(II) complexes. J Biol Inorg Chem 16: 195-208.

36. Fujimoto S, Yasui H, Yoshikawa Y (2012) Development of a novel antidiabetic zinc complex with an organoselenium ligand at the lowest dosage in KK-A mice. J Inorg Biochem 121: 10-15.

37. Promislow JH, Goodman-Gruen D, Slymen DJ, Barrett-Connor E (2002) Retinol intake and bone mineral density in the elderly: the Rancho Bernardo Study. J Bone Miner Res 17: 1349-1358.

38. Cline RR, Worley MM (2006) Osteoporosis health beliefs and self-care behaviors: an exploratory investigation. J Am Pharm Assoc 46: 356-363.

39. Janovská Z (2012) Bisphosphonate-related osteonecrosis of the jaws. A severe side effect of bisphosphonate therapy. Acta Medica (Hradec Kralove) 55: $111-115$

40. Le Goff B, Guillot P, Glémarec J, Berthelot JM, Maugars Y (2010) A comparison between bisphosphonates and other treatments for osteoporosis. Curr Pharm Des 16: 3037-3044.

41. Tucker KL, Hannan MT, Kiel DP (2001) The acid-base hypothesis: diet and bone in the Framingham Osteoporosis Study. Eur J Nutr 40: 231-237.

42. Zhu K, Devine A, Prince RL (2009) The effects of high potassium consumption on bone mineral density in a prospective cohort study of elderly postmenopausa women. Osteoporos Int 20: 335-340.

43. Miyahara T, Kozuka H (1985) The Direct Effect of Cadmium on Bone Metabolism and Interaction between Cadmium and Zinc or Copper in Tissue Culture. EISEI KAGAKU 31: 59-71.

44. Yamaguchi M, Sakashita T (1986) Enhancement of vitamin D3 effect on bone metabolism in weanling rats orally administered zinc sulphate. Acta Endocrino (Copenh) 111: 285-288.

45. Yamaguchi M, Ozaki K, Suketa Y (1989) Alteration in bone metabolism with increasing age: effects of zinc and vitamin D3 in aged rats. J Pharmacobiodyn 12: $67-73$

46. Karieb S, Fox SW (2012) Zinc modifies the effect of phyto-oestrogens on osteoblast and osteoclast differentiation in vitro. Br J Nutr 108: 1736-1745.

47. Tokudome Y, Otsuka M (2012) Possibility of alveolar bone promoting enhancement by using lipophilic and/or hydrophilic zinc related compounds in zinc-deficient osteoporosis rats. Biol Pharm Bull 35: 1496-1501.

48. Uchiyama S, Yamaguchi M (2003) Alteration in serum and bone componen findings induced in streptozotocin-diabetic rats is restored by zinc acexamate. Int J Mol Med 12: 949-954

49. Yamaguchi M, Uchiyama S, Ishiyama K, Hashimoto K (2006) Oral administration in combination with zinc enhances beta-cryptoxanthin-induced anabolic effects on bone components in the femoral tissues of rats in vivo. Biol Pharm Bull 29: 371-374.

50. Yamaguchi M, Inamoto K, Suketa Y (1986) Effect of essential trace metals on bone metabolism in weanling rats: comparison with zinc and other metals actions. Res Exp Med (Berl) 186: 337-342

51. Michigami K, Yoshikawa Y, Kajiwara N, Yasui H (2012) Bone strength increasing effect of $\mathrm{ZnSO}_{4}$ to osteoporosis SAMP6 mice. $19^{\text {th }}$ Meeting of Japanese Society of Hemorheology.

52. Koide T, Yuguchi M, Kawakita M, Konno H (2002) Metal-assisted stabilization and probing of collagenous triple helices. J Am Chem Soc 124: 9388-9389. 